\title{
Cerebral Aneurysm in Takayasu's Arteritis: A Case Report and Review of the Literature
}

\section{Aneurisma cerebral na arterite de Takayasu: relato de caso e revisão da literatura}

\author{
Breno Bezerra Arruda Câmara1,2 Marcos Antônio Dellaretti Filho ${ }^{2}$ Carlos Eduardo Romeu de Almeida ${ }^{2}$ \\ Daniel Espíndola Ronconi ${ }^{2}$ Marco Aurélio Vieira Couto ${ }^{2}$ Renata Ferreira de Souza ${ }^{2}$ \\ ${ }^{1}$ Instituto de Ensino e Pesquisa, Santa Casa de Belo Horizonte, Belo \\ Horizonte, Minas Gerais, Brazil \\ 2 Neurosurgery, Santa Casa de Misericórdia de Belo Horizonte, Belo \\ Address for correspondence Breno Bezerra Arruda Câmara, MD, \\ Instituto de Ensino e Pesquisa da Santa Casa de Belo Horizonte, Belo \\ Horizonte, Minas Gerais, Brazil (e-mail: breno_bac@yahoo.com.br).
} Horizonte, Minas Gerais, Brazil

Arq Bras Neurocir 2016;35:218-221.
Abstract
Keywords
- Takayasu's arteritis
- cerebral aneurysm
- subarachnoid hemorrhage

\section{Resumo \\ Palavras-chave \\ - arterite de Takayasu \\ - aneurisma cerebral \\ - hemorragia subaracnoidea}

Cerebral aneurysms are rarely observed in patients with Takaysu's arteritis. To our knowledge, this report presents the first case described in Brazil. Hemodynamic stress caused by obstructions of the cervical vessels developes cerebral aneurysms in these patients and they have higher rates of multiple and posterior circulation aneurysms than general population. In the majority of cases, microsurgical treatment is indicated mainly due to changes in the cervical vessels that preclude an endovascular approach.

Aneurismas cerebrais são raramente observados em pacientes com arterite de Takayasu. Este é o primeiro caso desta associação descrito no Brasil. O estresse hemodinâmico causado pelas obstruções vasculares cervicais desenvolve os aneurismas cerebrais nestes pacientes e eles apresentam maiores taxas de aneurismas múltiplos e de acometimento da circulação cerebral posterior. Na maioria dos casos, o tratamento microcirúrgico está indicado pois as alterações anatômicas dos vasos cervicais dificultam a abordagem endovascular.

\section{Introduction}

Takayasu's arteritis is a chronic inflammatory disease that affects medium and large caliber arteries, particularly the aorta and its main branches. ${ }^{1}$ Cerebral aneurysms and subarachnoid hemorrhage are rarely observed in these patients, and only 25 cases have been described in the literature. Hemodynamic stress seems to be of crucial importance in the anatomical distribution of cerebral aneurysms. ${ }^{2-5}$ Treatment follows the same criteria as those for the general population. ${ }^{5}$ The purpose of this study was to report the first known case in Brazil and review the literature.

received

April 2, 2016

accepted

June 8, 2016

published online

August 3, 2016
DOI http://dx.doi.org/ 10.1055/s-0036-1586238 ISSN $0103-5355$.

\section{Case Report}

In 2003, 11 years before our evaluation, a female patient attended a routine medical evaluation in which the absence of left radial pulse was identified. She was referred to a cardiologist, who suspected Takayasu's arteritis and prescribed a carotid duplex scan that indicated $70-80 \%$ stenosis in the common carotid arteries. A duplex scan of the lower limbs showed no changes. Aortography showed: $80 \%$ steno-

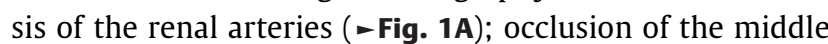
third of the subclavian arteries and extensive collateral branches to the intercostal arteries; $80 \%$ stenosis of the

Copyright $\odot 2016$ by Thieme Publicações License terms Ltda, Rio de Janeiro, Brazil

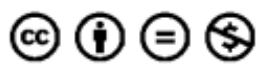


common carotid arteries (- Fig. 1B); occlusion of the right external carotid artery; and $95 \%$ stenosis of the right vertebral artery and dominant left vertebral artery. A cerebral angiography identified bilateral paraclinoid aneurysms close to the emergence of the ophthalmic arteries (measuring $5 \mathrm{~mm}$ and $1 \mathrm{~mm}$ ).

The patient's treatment began with prednisone, methotrexate and folic acid in 2004, with follow-up every six months, and no reports of clinical worsening or complications. In December 2011, she became pregnant and was referred to the Santa Casa de Belo Horizonte due to high obstetric risk. The patient developed pregnancy-specific hypertensive disorder, so the birth was performed by caesarean section without complications, followed by tubal ligation, and the normalization of blood pressure at two months postpartum.

In January 2014, at 27 years old, she was submitted to a new cerebral angiography at Santa Casa de Belo Horizonte that confirmed the presence of bilateral paraclinoid aneurysms (-Fig. 1C-D); the left aneurysm was larger $(6.1 \mathrm{~mm}$ and $2.2 \mathrm{~mm})$. She was then referred for treatment of the cerebral aneurysms. Upon admission, she was asymptomatic, and showed no evidence of any event or neurological symptoms, while the physical examination demonstrated impalpable brachial and radial pulses, a mild aortic diastolic murmur, and lower blood pressure in her arms. All laboratorial tests and inflammatory markers were normal.
The patient was submitted to treatment by microsurgery using the left pterional craniotomy approach and clipping of the left and right aneurysms (-Fig. 1E-F).

In the immediate postoperative period, she developed left amaurosis, but presented no other complications during hospitalization. A control arteriography was performed, showing complete exclusion of the aneurysms. One month later, while attending the outpatient clinic, she continued to present the amaurotic symptoms, but showed good performance status in everyday activities, scoring 90 on the Karnofsky Performance Scale.

\section{Discussion}

Takayasu's arteritis is a chronic inflammatory disease and a rare type of primary inflammatory vasculitis of unknown cause that affects medium and large caliber arteries, including the aorta and its main branches. ${ }^{1}$

Its pathophysiology includes transmural granulomatous inflammation with fibrinoid necrosis, which can result in vascular stenosis, occlusion, dilation and the formation of aneurysms. $^{6,7}$ Takayasu's arteritis is a rare disease that primarily affects young women and presents higher incidence in Asian countries, but it is not limited to these regions. $^{8,9}$

The clinical pathology is characterized by a systemic inflammatory phase, associated with other nonspecific systemic symptoms, such as fever, weight loss, sweating,

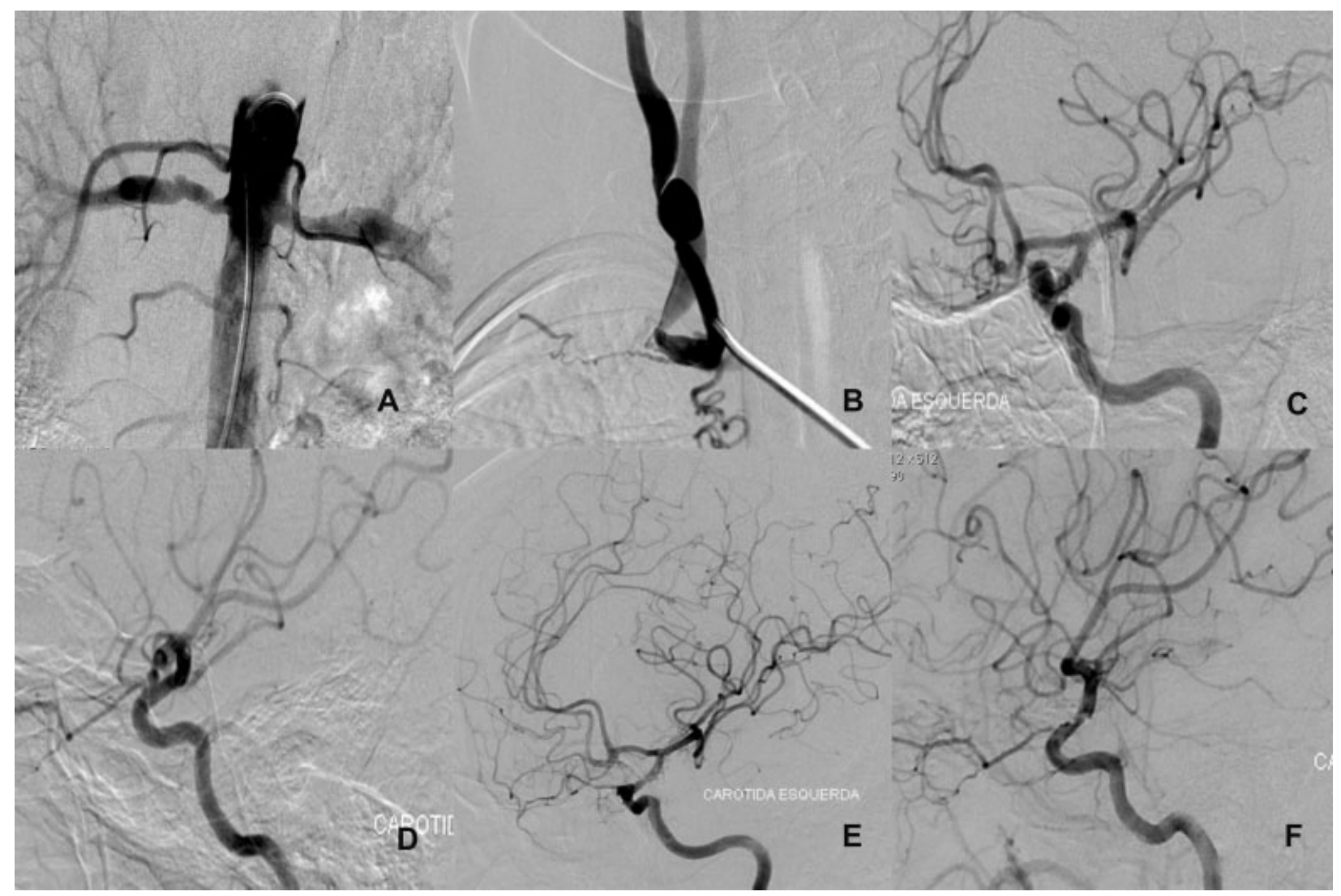

Fig. 1 (A) Aortography shows bilateral stenosis of the renal arteries. (B) Stenosis and dilations of the common carotid artery. (C) Aneurysm of the left ICA. (D) Baby aneurysm of the right ICA. (E and F) Control arteriography showing complete exclusion of the aneurysms. 
myalgia, arthralgia, anorexia and asthenia. A vascular inflammation phase follows, characterized by pain in the course of the affected vessel, and it culminates in the final stage, characterized by fibrosis of the vessels and ischemia, clinically represented by changes in pulse, arterial murmurs and tremors, paresthesia and claudication, mainly in the arms. $^{10,11}$

Diagnosis depends on the fulfillment of at least three of the American College of Rheumatology criteria, which are: patient age $<40$ years old; decreased brachial pulses; claudication of

Table 1 Summary of reported cases of cerebral aneurysms associated with Takayasu arteritis

\begin{tabular}{|c|c|c|c|}
\hline Report (year) & Age/sex & Symptom & Location \\
\hline Niitsu (1972) & $26 \mathrm{Y} / \mathrm{F}$ & sSAH & Lt. ICA-PComA \\
\hline Izawa (1980) & $55 \mathrm{Y} / \mathrm{F}$ & sSAH & Lt. VA \\
\hline Kumagai (1981) & $41 \mathrm{Y} / \mathrm{F}$ & sSAH & $\begin{array}{l}\text { BA } \\
\text { Lt. PCA }\end{array}$ \\
\hline Kumagai (1981) & $55 \mathrm{Y} / \mathrm{F}$ & sSAH & Bil. SCA \\
\hline Arita (1981) & $48 \mathrm{Y} / \mathrm{F}$ & Incidental & AComA \\
\hline Imaizumi (1982) & $48 \mathrm{Y} / \mathrm{F}$ & sSAH & AComA \\
\hline Masuzawa (1982) & $26 Y / F$ & sSAH & $\begin{array}{l}\text { Lt. PComA } \\
\text { Lt. MCA }\end{array}$ \\
\hline Masuzawa (1982) & $54 \mathrm{Y} / \mathrm{F}$ & sSAH & BA top \\
\hline Satoh (1983) & $38 Y / F$ & sSAH & Rt. ACA \\
\hline Matsuzawa (1984) & $55 \mathrm{Y} / \mathrm{M}$ & sSAH & Rt. VA \\
\hline Wakabayashi (1985) & $56 \mathrm{Y} / \mathrm{F}$ & sSAH & BA top \\
\hline Mizuno (1985) & $58 \mathrm{Y} / \mathrm{F}$ & sSAH & $\mathrm{BA}$ \\
\hline Masuzawa (1986) & $64 Y / F$ & sSAH & $\begin{array}{l}\text { Lt. ICA-OphA } \\
\text { Lt. ICA- PComA } \\
\text { BA top } \\
\text { AICA }\end{array}$ \\
\hline Kurimoto (1987) & $48 \mathrm{Y} / \mathrm{F}$ & sSAH & AComA \\
\hline Sunami (1987) & $58 \mathrm{Y} / \mathrm{F}$ & sSAH & $\begin{array}{l}\text { VA } \\
\text { Rt. PCA }\end{array}$ \\
\hline 'Dimitrijevic' (1989) & $53 \mathrm{Y} / \mathrm{F}$ & SSAH & MCA \\
\hline Nishimura (1994) & $48 \mathrm{Y} / \mathrm{F}$ & sSAH & $\begin{array}{l}\text { AComA } \\
\text { Lt. ICA } \\
\text { Rt. MCA }\end{array}$ \\
\hline Asaoka (1998) & $54 \mathrm{Y} / \mathrm{F}$ & Incidental & $\begin{array}{l}\text { AComA } \\
\text { Lt. ICA }\end{array}$ \\
\hline Kanda (2004) & $48 \mathrm{Y} / \mathrm{F}$ & sSAH & Rt. VA \\
\hline Sonwalkar (2004) & $50 \mathrm{Y} / \mathrm{F}$ & sSAH & $\begin{array}{l}\text { Lt. ICA-OphA } \\
\text { Lt. ICA- PcomA }\end{array}$ \\
\hline Takayama (2008) & $70 \mathrm{Y} / \mathrm{F}$ & Incidental & $\begin{array}{l}\text { BA top } \\
\text { Lt. PCA }\end{array}$ \\
\hline Weiss (2008) & $18 \mathrm{M} / \mathrm{F}$ & sSAH & $\begin{array}{l}\text { Rt. ACA } \\
\text { Lt. ICA }\end{array}$ \\
\hline Maramattom (2010) & $29 Y / M$ & sSAH & AComA \\
\hline He (2013) & $30 \mathrm{Y} / \mathrm{F}$ & sSAH & AComA \\
\hline $\mathrm{He}(2013)$ & $55 \mathrm{Y} / \mathrm{F}$ & Incidental & $\begin{array}{l}\text { BA top } \\
\text { Lt. PCA } \\
\text { AcomA }\end{array}$ \\
\hline Present case & $27 \mathrm{Y} / \mathrm{F}$ & Incidental & Bil. ICA- OphA \\
\hline
\end{tabular}

Abbreviations: ACA, anterior cerebral artery; AComA, anterior communicating artery; AICA, anterior inferior cerebellar artery; BA, basilar artery; $F$, female; Bil., bilateral; ICA, internal carotid artery; Lt., left; M, male; MCA, middle cerebral artery; OphA, ophthalmic artery segment; PCA, posterior cerebral artery; PComA, posterior communicating artery; Rt., right; SCA, superior cerebellar artery; sSAH, spontaneous subarachnoid hemorrhage; VA, vertebral artery; Y, years. Adapted from Takayama et al ${ }^{20}$ (2008), Kanda et al ${ }^{4}$ (2004), and Masuzawa et al ${ }^{15}$ (1984). 
the extremities; a difference in systolic blood pressure in the upper limbs greater than $10 \mathrm{~mm} \mathrm{Hg}$; murmurs in the subclavian arteries and aorta; and angiographic changes in the aorta and its main branches. A combination of these criteria shows $90.5 \%$ sensitivity and $97.8 \%$ specificity. ${ }^{9,12}$

Involvement of the central nervous system occurs in $20 \%$ of patients, usually through ischemic stroke. ${ }^{13}$ In contrast, cerebral aneurysms and subarachnoid hemorrhage are very rare presentations, ${ }^{4}$ with only 25 cases currently described in the literature.

In our review of the literature, we found 22 papers reporting 18 aneurysms in the posterior circulation, and 24 in the anterior circulation, in which the internal carotid, anterior communicating and basilar arteries were the most affected (- Table 1). ${ }^{4,5,14-20}$ Thus, the proportion of involvement of the posterior circulation in these patients is much higher (42.8\%) than in the general population, ${ }^{5,14}$ where $~$ $90 \%$ of aneurysms occur in the anterior circulation. The hemodynamic stress caused by the obstruction or occlusion of the carotid system is considered the main factor related to the genesis of cerebral aneurysms in Takayasu's arteritis, since the majority of studies observed no inflammation in the intracranial vessels affected. ${ }^{2-5}$ Studies using animal models, in which occlusion of the neck vessels was performed, led to the development of intracranial aneurysms that mimicked the pathophysiology proposed. ${ }^{2}$ Only one patient showed no stenosis in the cervical vessels. ${ }^{4}$ These patients also have a higher incidence of multiple aneurysms $^{14}$ ( 11 of the 25 cases reported).

The treatment of cerebral aneurysms in Takayasu's arteritis follows the same recommendations as those for the general population. ${ }^{5}$ He et al report the control of inflammatory markers before neurosurgical treatment in their two cases, ${ }^{5}$ but there is no evidence for delaying treatment for this reason. Masuzawa et al highlight the importance of treating these aneurysms, since these patients usually have high blood pressure that is often difficult to control, increasing the risk of complications related to cerebral aneurysm. The permanence of hemodynamic stress caused by arterial blockages also favors the risk of rupture or the appearance of new aneurysms. ${ }^{15}$ Microsurgical treatment is recommended in most cases because, as described by Maramattom, the presence of altered anatomical cervical vessels, whether due to stenosis, dilations or accentuated tortuosity, can make access to the aneurysm by the endovascular approach unfeasible. ${ }^{16}$ In this case, the cervical vessels stenosis and the aneurysm neck size $(7 \mathrm{~mm})$ were relevant in the surgical decision.

\section{Conclusion}

Despite the inflammatory involvement of vessels in Takayasu's arteritis, causing stenosis and dilation, these alterations are rarely found in the cerebral circulation. ${ }^{4}$ The case reported here is a rare association of two infrequent pathologies, and there is no evidence of causality between them, ${ }^{14}$ but this association has specific characteristics that directly influence its management. The anatomical aspects and the patient's condition shall define the best treatment. ${ }^{4}$

\section{References}

1 Kerr GS. Takayasu's arteritis. Rheum Dis Clin North Am 1995; 21(4):1041-1058

2 Hashimoto N, Handa H, Hazama F. Experimentally induced cerebral aneurysms in rats. Surg Neurol 1978;10(1):3-8

3 Shigemori M, Kojo N, Miyagi J, Watanabe M, Kuramoto S. Agenesis of the left internal carotid artery associated with an aneurysm of the anterior communicating artery. Neurol Med Chir (Tokyo) 1980;20(1):73-79

4 Kanda M, Shinoda S, Masuzawa T. Ruptured vertebral arteryposterior inferior cerebellar artery aneurysm associated with pulseless disease-case report. Neurol Med Chir (Tokyo) 2004; 44(7):363-367

5 He FL, Zhang HQ Gu YQ, Li XF, Li JX, Zhang J. Treatment of cerebral aneurysms associated with Takayasu arteritis. Chin Med J (Engl) 2013;126(3):597-599

6 Seko Y. Takayasu arteritis: insights into immunopathology. Jpn Heart J 2000;41(1):15-26

7 Hoffman GS. Takayasu arteritis: lessons from the American National Institutes of Health experience. Int J Cardiol 1996;54 (Suppl):S99-S102

8 Numano F. Differences in clinical presentation and outcome in different countries for Takayasu's arteritis. Curr Opin Rheumatol 1997;9(1):12-15

9 Panico MDB, Spichler ES, Rodrigues LCD, et al. Takayasu's arteritis: clinical and therapeutic aspects in 36 patients. J Vasc Bras 2008; 7(2):123-130

10 Kerr GS, Hallahan CW, Giordano J, et al. Takayasu arteritis. Ann Intern Med 1994;120(11):919-929

11 Souza AWS, Neves RMS, Oliveira KR, Sato EI. Takayasu's arteritis treatment. Rev Bras Reumatol 2006;46(Suppl 1):2-7

12 Arend WP, Michel BA, Bloch DA, et al. The American College of Rheumatology 1990 criteria for the classification of Takayasu arteritis. Arthritis Rheum 1990;33(8):1129-1134

13 Weiss PF, Corao DA, Pollock AN, Finkel TH, Smith SE. Takayasu arteritis presenting as cerebral aneurysms in an 18 month old: A case report. Pediatr Rheumatol Online J 2008;6:4

14 Nishimura S, Suzuki M, Mizoi K, Yoshimoto T. Multiple cerebral aneurysms associated with aortitis syndrome-case report. Neurol Med Chir (Tokyo) 1994;34(12):821-824

15 Masuzawa T, Shimabukuro H, Furuse M, Fukushima K, Kasuda H, Sato F. Pulseless disease associated with a ruptured intracranial vertebral aneurysm. Neurol Med Chir (Tokyo) 1984;24(7): 490-494

16 Maramattom BV. Coil embolization of a ruptured anterior communicating aneurysm in Takayasu's arteritis. Neurol India 2010; 58(1):137-139

17 Imaizumi S, Nagamine Y, Nakamura N, Katakura R, Higuchi H. [Aneurysm of anterior communicating artery associated with aortitis syndrome-a treated case by aneurysmal neck clipping (author's transl)]. No Shinkei Geka 1982;10(4):449-455

18 Dimitrijević J, Dzirlo K, Stanković D, Simić L, Bokonjić R. [Takayasu's disease and cerebromeningeal hemorrhage]. Rev Neurol (Paris) 1989;145(6-7):466-469

19 Sonwalkar HA, Gupta AK, Purkayastha S, Bodhey NK, Krishnamoorthy T. Takayasu arteritis with multiple intracranial aneurysms. A case report. Interv Neuroradiol 2004;10(3): 249-252

20 Takayama K, Nakagawa H, Iwasaki S, et al. Multiple cerebral aneurysms associated with Takayasu arteritis successfully treated with coil embolization. Radiat Med 2008;26(1):33-38 